\title{
Demand Elasticities at the Intensive and Extensive Margins for Advertising Mail Traffic in the UK
}

\author{
Frédérique Fève, Thierry Magnac, and Soterios Soteri
}

\section{Introduction}

Advertising letter mail competes for marketing budgets against a range of different media types. Since the early 2000s, its share of total advertising expenditure in the UK declined by approximately half to account for less than a tenth by the end of 2018. ${ }^{1}$ However, advertising mail remains an important component of UK letter volumes, accounting for over three billion items and around a third of addressed inland letters in 2018. A number of factors impact the demand for advertising letters, some outside the control of postal operators and decision-makers (such as economic conditions and advances in new technology), but price is a factor that can influence demand. Here we investigate advertising price elasticities using a rich source of UK customer data.

Senders of advertising mail in the UK tend to be large mailers who can choose among several types of advertising letter products that differ in format type, speed of delivery, and level of sortation. ${ }^{2}$ Furthermore, customers can choose a Royal Mail end-to-end advertising retail product or a network access service offered by com-

\footnotetext{
${ }^{1}$ Estimates informed by figures from various World Advertising Research Center (WARC) Expenditure Reports.

${ }^{2}$ For example, to use a Royal Mail advertising mail product, a customer needs to mail a minimum of 1000 letters or parcels, and parcels or 250 large letters.
}

\footnotetext{
*The views expressed in this paper are those of the authors and do not necessarily reflect those of their affiliated organizations.

F. Fève $\cdot$ T. Magnac $(\bowtie)$

Toulouse School of Economics, University of Toulouse, Toulouse, France

e-mail: thierry.magnac@tse-fr.eu

S. Soteri

Royal Mail Group, London, UK
} 
petitors that handle the upstream elements of a postal operation (in particular, collection, sortation, and trunking services) and then pay Royal Mail an access price per item to deliver letters to recipients.

Within such an environment, this study uses a large panel of Royal Mail retail customers to estimate advertising price elasticities and provide some new insights to the postal economics literature. In particular, this chapter extends our estimation of price elasticities reported in Fève et al. (2018) for advertising letters in the UK using a large panel of customers. In our previous paper, elasticities at the intensive margin were estimated by restricting data to effective customers of each product, i.e., those consuming a positive quantity of a product. There are many customers, however, who do not consume every type of product in each period (around $95 \%$ of observations are zero), and this likely affects the estimation of elasticities. In order to take this into account, this paper estimates price elasticities at the extensive margin by analyzing the customer's binary response to consume, or not, each product when prices change. Our model provides both own-price and cross-price elasticity estimates at the intensive margin and at the extensive margin. We use a data set covering Royal Mail addressed retail advertising customers over the period 2011-2017 to estimate price elasticities that take into account customer characteristics such as sector and firm size.

Section 2 describes the data and estimation methodology for modelling price elasticities at the intensive and the extensive margins. Section 3 contains results. Section 4 provides a summary and conclusion.

\section{Modeling Demand for Advertising Traffic}

The econometric analysis, whose results are reported in this chapter, uses a rich data set of Royal Mail retail customers, to estimate price elasticities for addressed letter advertising traffic. The individual customer data were grouped into eight product categories $(m=8)$, consisting of two sortation levels (low and high sort), and two speeds of delivery (second class and economy), for each of two letter format sizes (standard and large). ${ }^{3}$ Information was available for $2640(=n)$ retail addressed advertising customers, for the period July 2011 to September 2017, and the data were aggregated on a quarterly time period basis, $t$. The customers contained in this data set accounted for almost a quarter of all addressed advertising sent in the UK over the time period examined. We excluded customers solely sending advertising mail via access operators over the entire period of the analysis, as these customers

\footnotetext{
${ }^{3}$ It would have been possible to differentiate product categories further, for example, by machinereadable font type or eco-friendly paper envelopes. However, Royal Mail product managers, in the first instance, tend to differentiate addressed advertising letters by speed, sortation, and format level, and this product grouping categorization was adopted. A further point to note is that customers infrequently send a relatively very small number of First-Class sorted advertising letters which have been excluded from this analysis.
} 
could not be identified. Furthermore, we do not have data on mail sent via access operators for the customers included in the database. Nonetheless, we condition the following analysis on the price of access products.

Price elasticities of letter demand are derived from the function relating letter traffic volumes, denoted by $Q_{i j t}$, sent by different customers, each denoted by $i$, for different types of letter mail products, denoted by $j$, during a quarter denoted by $t$, and the level of prices charged to send mail, denoted by $p$, and environmental exogenous variables denoted by $X$. Where data are available on these variables for $n$ customers during $T$ periods, the demand function is written as:

$$
Q_{i j t}=f\left(P_{i j t}, X_{i j t}, u_{i j t}\right) \quad i=1, \ldots, n, j=1, \ldots, m \text { and } t=1, \ldots, T \text {. }
$$

where $u$ is a random error term

It is unlikely that customers use every product type at every time period. The set of observations for which demand, $Q_{i j t}$, is positive constitutes fewer than $4 \%$ of the total number of observations. ${ }^{4}$ Note however that:

$$
E\left(Q_{i j t} \mid p_{i j t} X_{i j t}\right)=E\left(Q_{i j t}\left|, p_{i j t}, X_{i j t}\right|, Q_{i j t}>0\right) \operatorname{Pr}\left(Q_{i j t}>0 \mid p_{i j t}, X_{i j t}\right),
$$

so that effects of prices are the composition of effects on expected demand when demand is positive and on the probability that demand is positive. Elasticities referring to the first term on the right-hand side are describing what happens at the intensive margin, while the effects referring to the second term are describing the extensive margin.

In our previous work (Fève et al. 2018), we estimated elasticities of demand at the intensive margin by considering only positive observations. In this paper, we first revisit the estimation of elasticities at the intensive margin and extend this analysis by estimating cross-price elasticities relative to a substitute, access products, to retail advertising letters. ${ }^{5}$ We then turn to the estimation of elasticities at the extensive margin. Those elasticities reflect competition with access advertising mail, which is clearly a direct substitute, and competition with other media. Evidence on the latter comes from two sources: firstly, direct customer information on reallocating budgets to other media (mainly digital) and, secondly, via econometric studies; see, for example, Veruete-McKay et al. (2011). Note however that, for the extensive margin, our estimates refer to the population of customers, having at least one positive demand for one product category during this period. We nevertheless control for "entry" and "exit" of these customers from any of these product markets over this period.

\footnotetext{
${ }^{4}$ The main reason for the relatively low number of non-zero observations is that customers do not simultaneously consume all eight product categories at each point in time. That is, customers do not send addressed advertising mail containing all levels of sortation, all speeds of delivery, and all format types in every three months of the year.

${ }^{5}$ Access products are collected and sorted by upstream competitors to Royal Mail, as well as some very large customers, who then transport it to a Royal Mail inward mail center prior to Royal Mail delivering it to its final destination.
} 


\subsection{Intensive Margin}

A traditional parametric econometric approach was used to estimate the demand function (1) using log-linear models in the 4\% sample of observations with positive values, similar to Fève et al. (2018), and took the following form:

$$
\begin{aligned}
\ln \left(Q_{i j t}\right)= & \alpha+\beta \ln \left(p_{i j t}\right)+\gamma_{1}\left(\ln \left(\text { size }_{i}\right) \ln \left(p_{i j t}\right)\right)+\gamma\left(\ln \left(\text { size }_{i}\right)\right) \\
& +\delta_{k} \text { dsector }_{k}+\lambda_{j} \text { dproduct }_{j}+\mu_{t} \text { dtime }_{t}+v_{i j t}
\end{aligned}
$$

Our enhanced specification introduces the price of access letter products (pa) in $\operatorname{logs}$ to estimate the cross-price elasticity of access and retail and takes the following form:

$$
\begin{aligned}
\ln \left(Q_{i j t}\right)= & \alpha+\beta \ln \left(p_{i j t}\right)+\gamma_{1}\left(\ln \left(\text { size }_{i}\right) \ln \left(p_{i j t}\right)\right)+\gamma\left(\ln \left(\text { size }_{i}\right)\right)+\delta_{k} \text { dsector }_{k} \\
& +\lambda_{j} \text { dproduct }_{j}+\mu_{t} \text { dtime }_{t}+\zeta \ln \left(p a_{j t}\right)+v_{i j t}
\end{aligned}
$$

with some variables, such as letter mail volumes $(Q)$, retail mail prices $(p)$ access prices $(p a)$, and customer size, are in logarithmic form denoted by $\ln ()$. Other environment variables, $X_{i j t}$, comprise three sets of dummy variables that account for sectoral heterogeneity of senders - dsector, describing $10(=k)$ sectors - for differences in products (dproduct), and time effects (dtime), to capture the impact of macroeconomic variables, e-substitution, and other external events. We do not allow for any dynamic impact of prices as the presence of adjustment costs or habit formation is unlikely or negligible.

We allow for heterogeneity in price responses of customers by including an interaction term between prices and customer size (size) in logarithms. This means that the own-price elasticity varies by customer size and is equal to $\beta+\gamma_{1} \ln ($ size $)$ as derived from expression (3). For simplicity, variable size is measured by the deviation of the number of employees of the customer, with respect to the sample average, as the price elasticity for the mean customer can be thus read as $\beta$.

The coefficient of the logarithm of access price, $\zeta$, directly reads as the crossprice elasticity for the mean customer. A note of caution is in order since this price is the compensation set by Royal Mail and does not include the relatively small mark-up added by access providers, as customer feedback on contracts lost to access operators indicate.

Furthermore, we use a logarithmic form for this equation for simplicity. This is the most common way of estimating elasticities in samples in which quantities are positive since the error term is unbounded from below.

There are still three technical issues. First, we assume that the error term is mean independent of regressors and therefore an absence of selection bias. Given the relatively small number of selected observations and the absence of any valid exclusion restrictions, it is difficult to envision how to deal with selection issues without strong functional form assumptions. We then assume away selection issues although this assumption could be questioned and potentially examined further in the light of a 
richer data as an extension to this chapter. This assumption can be justified by using the literature on the infrequency of purchases dealing with purchases of customers at (conditionally on regressors) infrequent times (see Deaton and Irish 1984).

Second, the technical appendix shows that the logarithmic specification does not affect the estimation of mean elasticities that would be obtained by modeling this equation in levels, provided that the error term, $v_{i j t}$, is independent of regressors instead of being mean independent only. The constant term, using a logarithmic form, might be biased but not mean elasticities as described by Eq. (1).

Third, ordinary least squares (OLS) estimates of Eq. (3) are likely to be biased, however, since customer prices for a specific letter product for each quarter, $p_{i j t}$, were derived by dividing customer revenue data, $R_{i j t}$, by the corresponding volume, $Q_{i j t}$. Measurement errors affecting volumes will impact prices and introduce a spurious correlation between the left-hand side variable and the right-hand side variables (see, for instance, Borjas 1980). Furthermore, Royal Mail used price discounts to incentivize customers to mail additional volumes (e.g., "incentive for growth schemes") that are also probably positively correlated with volumes. To correct for endogeneity, we use 2SLS estimation techniques and the standard rate card price, $p_{i j t}{ }^{0}$, as an instrument. It affects prices $p_{i j t}$ and is excluded from Eq. (3).

The estimation proceeded as follows. Firstly, an instrumental variable auxiliary equation was estimated by regressing the endogenous variable $\ln \left(p_{i j t}\right)$, the price paid by firms; on the rate card, $\ln \left(p_{i j t}{ }^{0}\right)$; the Royal Mail pre-announced publicly published price $^{6}$; and on any other variables appearing in model (3). Second, instead of replacing the endogenous variable by its predictor, derived from the instrumental equation, two-stage least squares (2SLS) estimates were obtained, by the equivalent procedure of including residuals from the instrumental variable equation (see Davidson and MacKinnon 2004). We estimate by OLS the augmented regressions:

$$
\begin{aligned}
\ln \left(Q_{i j t}\right)= & \alpha+\beta \ln \left(p_{i j t}\right)+\gamma_{1}\left(\ln \left(\text { size }_{i}\right) \ln \left(p_{i j t}\right)\right)+\gamma\left(\ln \left(\text { size }_{i}\right)\right)+\delta_{k} \text { dsector }_{k} \\
& +\lambda_{j} \text { dproduct }_{j}+\mu_{t} \text { dtime }_{t}+\psi \hat{u}_{i j t}+\varphi \ln \left(\text { size }_{i}\right) \hat{u}_{i j t}+\zeta \ln (\text { pa })+v_{i j t}
\end{aligned}
$$

in which $\hat{u}_{i j t}$ is the residual constructed from the instrumental regressions in each sector with $\ln \left(p_{i j t}\right)$ as the dependent variable, and as explanatory variables, all variables (except price) included in model (3).

\subsection{Extensive Margin}

The structure of the data is such that quantities are equal to zero and prices are missing whenever product $j$ is not consumed by firm $i$ during quarter $t$. There are many zeros in the data (more than 95\%) and this is likely to affect the estimation of price elasticities.

\footnotetext{
${ }^{6}$ The price paid by large senders of advertising mail tends to be subject to competitive tenders and can differ to the standard rate card price publicly available at the time.
} 
In this section, we take into account the effect that prices have on the binary variable, describing whether each firm reports consumption of product $j$ at time t, or not. We consider the full sample of firm-product-quarter and we write:

$$
\left.\begin{array}{ll}
Q_{i j t}>0 & \text { if } \ln p_{i j t}^{0}+z_{i j t} \gamma_{z}+v_{i j t}>0 \\
Q_{i j t}=0 & \text { if not, }
\end{array}\right\}
$$

in which, $p_{i j t}^{0}$, denotes again the rate card price, assumed to be exogenous to individual firm actions since it is determined in advance by Royal Mail at the market level. We use the same exogenous shift variables as in model (3) above. Such that variables $z_{i j t}$ are dummies for products, sectors and time (quarters), as well as the logarithm of access prices, $\ln (p a)$, customer size, $\ln \left(\right.$ size $\left._{i}\right)$ and its interaction with $\log$ prices, $\left(\ln \left(\right.\right.$ size $\left.\left._{i}\right) \ln \left(p_{i j t}^{0}\right)\right)$. Errors, $v_{i j t}$, are assumed to be normally or logistically distributed so that parameters, $\gamma$ and $\gamma_{z}$, are estimated by parametric methods such as Probit or Logit.

For Probit we can write:

$$
\operatorname{Pr}\left(Q_{i j t}>0 \mid \ln p_{i j t,}^{0} z_{i j t}\right)=\Phi\left(\gamma \ln p_{i j t}^{0}+z_{i j t} \gamma_{z}\right)
$$

in which $\Phi$ is the cumulative distribution of the normal.

Taking a step back, note that the full average elasticity at both intensive and extensive margins is equal to:

$$
\frac{1}{E\left(Q_{i j t} \mid \log p_{i j t}^{0}, z_{i j t}\right)} \frac{\partial E\left(Q_{i j t} \mid \log p_{i j t}^{0} z_{i j t}\right)}{\partial \log p_{i j t}^{0},},
$$

which, in turn, is equal to the composition of elasticities at the intensive and extensive margins ${ }^{7}$ :

$$
\underbrace{\varepsilon_{i}}_{\text {Intensivemargin }}+\underbrace{\gamma \frac{\varphi\left(\gamma \ln p_{i j t}^{0}+z_{i j t} \gamma_{z}\right)}{\phi\left(\gamma \ln p_{i j t}^{0}+z_{i j t} \gamma_{z}\right)}}_{\text {Extensivemargin }}
$$

In which $\varepsilon_{i}$ is the estimated average own-price elasticity obtained using Eq. (3). To obtain this result, we assumed that the derivative of the true log prices underlying the observed $\log$ prices, $\ln \left(p_{i j t}\right)$ with respect to $\ln \left(p_{i j t}^{0}\right)$ is equal to 1 . This is how we can make both elasticities at the intensive and extensive margin comparable. Hypotheses postulating other values of the elasticity of true prices to the rate card, set by Royal Mail, can also be considered.

\footnotetext{
${ }^{7} \mathrm{~A}$ technical appendix detailing these computations is available upon request from the authors.
} 
Returning to the estimation of the elasticity at the extensive margin, we use generalized estimating equations in panels (Liang and Zeger 1986) and allows for different within-customer correlation structure over time. More specifically, we use the setting of Pan (2001), as updated by Hin and Wang (2009), for selecting the best covariance structure.

\section{Estimated Price Elasticities for Retail Addressed Advertising Mail}

In this section, we report estimation results on models (3) and (5) and in particular estimates of average elasticities at the intensive and extensive margins.

\subsection{Intensive Margin}

Table 1 reports the estimated coefficients for the price effects and their respective standard errors for models (2) and (3), and the appendix contains further information on estimates. Recall that model (2) was estimated by Fève et al. (2018), and results are reported for the purpose of comparing them to our new results when we estimate cross-price elasticities as well. We therefore focus on the estimates of model (3) which suggest that retail advertising customer price elasticities tend to increase in absolute terms with customer size and that the average elasticity is around -1.15 (95\% confidence interval, $[-0.76,-1.55])$. It is a significantly larger elasticity than the one obtained when we omit the log-price of access products (e.g., model 2) even if the $95 \%$ confidence intervals overlap. A possible specification test

Table 1 Retail addressed advertising mail estimated price elasticities at the intensive margin

\begin{tabular}{|c|c|c|c|}
\hline \multicolumn{2}{|l|}{ Model (2) } & \multicolumn{2}{|l|}{ Model (3) } \\
\hline Coefficient & Standard error & Coefficient & Standard error \\
\hline \multicolumn{2}{|c|}{$\begin{array}{l}\text { Estimated aggregate own-price elasticity }(\beta) \\
\text { varies by customer size }(\gamma)\end{array}$} & \multicolumn{2}{|c|}{$\begin{array}{l}\text { Estimated aggregate own-price elasticity }(\beta) \\
\text { varies by customer size }(\gamma) \\
\text { Estimated aggregated cross-price elasticity }(\zeta)\end{array}$} \\
\hline$\beta=-0.71 * * *$ & $(0.21)$ & $\beta=-1.15 * * *$ & $(0.20)$ \\
\hline \multirow[t]{2}{*}{$\gamma=-0.06 * * *$} & \multirow[t]{2}{*}{$(0.01)$} & $\gamma=-0.06 * * *$ & $(0.01)$ \\
\hline & & $\zeta=1.50 * *$ & $(0.42)$ \\
\hline No. of obs. 34,075 & $\begin{array}{l}F(45, \\
34,029)=383.5\end{array}$ & No. of obs. 34,075 & $\begin{array}{l}F(47, \\
34,027)=368.7\end{array}$ \\
\hline$R^{2}=0.34$ & Prob $>F=0.0000$ & $R^{2}=0.34$ & Prob $>F=0.0000$ \\
\hline Adjusted $R^{2}=0.34$ & $\mathrm{RMSE}=1.3191$ & Adjusted $R^{2}=0.34$ & RMSE $=1.3182$ \\
\hline
\end{tabular}

Notes: $*$ Denotes statistically significant at $10 \%$ level, $* *$ at $5 \%$ level, and $* * *$ at $1 \%$ level Figures in parenthesis are standard errors for price coefficients 
between the two models is obtained by testing the absence of significance of the latter price, and this hypothesis is strongly rejected - its Student t-statistic is equal to 3.57 . The cross-price elasticity is significantly positive and quite large although the $95 \%$ confidence interval is quite wide $([0.66,2.34])$. The reason why the omitted variable bias in model 2 goes in the direction of a lower elasticity is likely to be that access and retail log-prices are positively correlated over time. The omission of the access log-price in model 2 therefore upward biases (i.e., makes it less negative) the coefficient of the retail log-price.

This colinearity issue, due to correlation of prices over time, also affects the estimated relative magnitude of the own- and cross-price elasticities. Note that since we estimate a single demand function for retail traffic, Slutsky cross-equation restriction with respect to access traffic cannot be estimated and tested. ${ }^{8}$ However, the property that demand is homogeneous of degree zero in prices implies that the sum of the impact of own-price and cross-price elasticities on demand should be equal to zero. In our case, the estimated cross-price elasticity is larger, in absolute value, than the estimated own-price elasticity and with a different sign. The higher absolute cross-price elasticity is likely to reflect two factors: firstly, the much higher level of expenditure on access advertising letters relative to retail traffic and, secondly, the presence of multi-colinearity between access and retail prices. Formal testing does not reject the hypothesis that the combined impacts of the retail ownand cross-price elasticities are equal and opposite in magnitude at the mean point (Student statistic equal to 1.10). Furthermore, the homogeneity property applies to all prices that affect firm production, and not only retail and access prices, so that even if the property was rejected, the evidence would be fragile. Nonetheless, via Slutsky restrictions, we can say that the corresponding cross-price elasticity for access traffic - which is unobservable at the customer level in our data - could potentially be around a third of our estimated retail cross-price elasticity because of the higher level of expenditure in access traffic (approximately three times retail expenditure). If this were the case and this cross-price elasticity were, say, 0.5 , then as long as the access own-price elasticity was $\leq-0.5$, total advertising letter demand would not increase as access prices increased.

The results reported in Table 1 also indicate that, in general, larger firms tend to be more price sensitive than smaller firms. This may be due to the greater flexibility that larger firms have with respect to access to other media advertising channels, such as digital or television. The demand elasticity $\varepsilon_{i}$, at the intensive margin, is estimated to be a function of customer size (measured by the number of employees of the organization sending mail), and the formula is $\varepsilon_{i}=-1.15-0.06 \ln$ (size). On average, the estimated price elasticity for a relatively small company (say 20 employees) is equal to around -1.10 and for a very large firm (say, more than 2000 employees) around -1.38 .

\footnotetext{
${ }^{8}$ Unfortunately, we do not have data on customers who switch from sending advertising mail via a Royal Mail retail product to an access operator service, and therefore we cannot directly estimate access customer cross-price elasticities.
} 


\subsection{Extensive Margin}

We fit generalized estimated equations (Liang and Zeger 1986) to estimate Eq. (5). We specify different within-product and customer correlation structures over time although we always assume independence between groups - i.e., at the productconsumer level. More specifically, we allow for different flexible time-varying correlations (unstructured or stationary with 20 lags) and less flexible structures like an autoregression structure (ar 1) or full independence over time. All estimates are consistent (Avery et al., 1983). Detailed results are reported in Table 2.

Results vary considerably with the correlation structure adopted. In particular, own-price elasticities vary from around -0.5 to -1 for unstructured and stationary correlation; -1.6 to around -2 for the AR 1 ; and -3 to -5 under independence.

A model selection procedure is therefore required to choose among these different estimates. Pan (2001) proposed such a procedure by using a quasi-likelihood information criterion (QIC) generalizing Akaike's. Hin and Wang (2009) refined this procedure for covariance structure selection by proposing another criterion, dominating QIC that they named, correlation information criteria (CIC). This statistic is reported in Table 2.

Unambiguously, minimizing CIC favors the selection of the results in the first column of Table 2 and indicates that the best estimates are obtained under a general unstructured correlation structure. However, it is noticeable that the standard errors for the own-price elasticities are quite large, and the estimated coefficients for the own-price elasticities are not statistically significant for either the Probit or Logit estimates. These large standard errors are related to the flatness of the CIC values which indicates that selecting the best model - across which elasticities vary - may be a close call. Cross-price elasticities are positive as expected, given the large substitutability between retail and access products. They are of the same magnitude as the own-price elasticities but they are highly significantly different from zero. Given the strong correlation between rate card and access prices, it is not unlikely that multi-colinearity is impacting the identification and precision of estimates for both elasticities.

\subsection{Full Price Elasticities: Adding Margins}

As shown by Eq. (6), the full elasticity is the sum of elasticities at the intensive and extensive margins. The elasticity at the intensive margin is estimated using a conditional model, while the elasticity at the extensive margin is estimated using a marginal model; these two estimates are independent and can be easily composed. Nonetheless, as mentioned above, we use different prices when computing elasticities at the intensive margin (the price effectively paid by the customer) and elasticities at the extensive margin (the rate cards set by Royal Mail). The relationship between these two prices is likely to vary on a near one-to-one basis such that the 


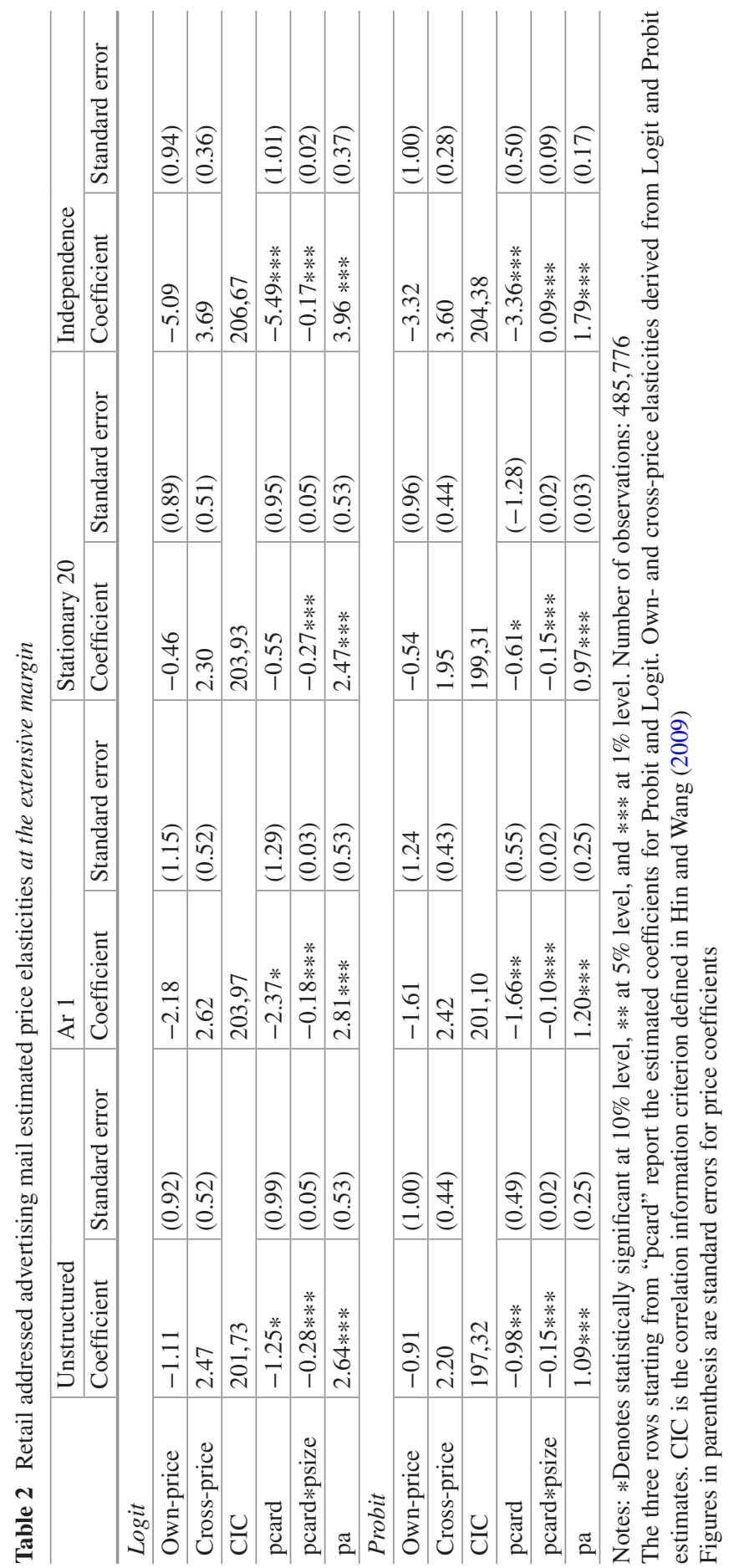


Table 3 Full price elasticities

\begin{tabular}{l|l|l}
\hline & Elasticity & Standard error \\
\hline Logit & \multicolumn{2}{|l}{} \\
\hline Own-price & -2.26 & $(0.94)$ \\
\hline Cross-price & 3.96 & $(0.67)$ \\
\hline Probit \\
\hline Own-price & -2.06 & $(1.02)$ \\
\hline Cross-price & 3.69 & $(0.61)$ \\
\hline
\end{tabular}

Figures in parenthesis are standard errors for price elasticities

full elasticity can be approximated by adding up the two-price terms (the intensive and extensive margins) as in Eq. (6).

Under this assumption, Table 3 reports the full own-price elasticity to be around -2 for Probit and Logit with a standard error around 1 and therefore significant at the 5\% level. This estimate is somewhat higher in absolute terms than those estimated in some other studies. In particular, Veruete-McKay et al. (2011) estimate own-price elasticities for direct mail in the UK to be in a range from -0.7 to -1.4 and Bzhilyanskaya et al. (2015) estimate USPS advertising own-price elasticities to be around -0.9 .

The full-cross-price elasticity is estimated to be approximately around 3.4 with a standard error equal to 0.45 , which makes it highly significant, and suggests that Royal Mail retail advertising products and competitor access products are intensively competing against each other. It is difficult to assess whether the extent of this competition is greater or less than in elsewhere as we are not aware of any other studies to directly compare our estimated cross-price elasticity effects. For example, Bzhilyanskaya et al. (2015) estimate much smaller advertising cross-price elasticities for competing product ranges, but it is not clear if these are for similarly close substitutes. ${ }^{9}$

\section{Conclusion}

In this paper, we have advanced and improved upon the conclusions of Fève et al. (2018) concerning the estimation of own-price elasticities of advertising letter traffic, in two directions. We first assessed the importance of including substitutable letter products, in particular access products. We found that, indeed, cross-price elasticities are significant, and the omission of such prices of substitutes biases downward own-price elasticities. Second, we estimated elasticities at the extensive

${ }^{9}$ For example, advertising cross-price elasticity estimates with respect to First-Class Mail and Periodical lie in the range 0.1-0.2 and are substantially lower than estimates reported in Table 2, possibly reflecting the fact that the USPS product groups contain mails that, in general, are used for different purposes. 
margin by using the binary decisions of all customers to consume or not each product over the entire sample period. Our results showed that these elasticities are sizeable but somewhat imprecisely estimated. An avenue for further research, which may help to improve on these results, is to examine the potential implications of any customer selection bias using, if possible, a richer data set.

In conclusion, we leave postal operators and policy makers with the following thoughts to help guide and inform future decision-making with respect to advertising mail: when taking into account factors impacting customers effective purchases (i.e., their intensive margin price elasticity impact) and assessing whether to purchase or not (their extensive margin price elasticity impact), advertising mail own-price elasticities are likely to be high (possibly around -2 in the UK) and competition with respect to close substitutes intense.

\section{References}

Avery, R. B., Hansen, L. P., \& Hotz, V. J. (1983). Multiperiod probit models and orthogonality condition estimation. International Economic Review, 24(1), 21-35.

Borjas, G. J. (1980). The relationship between wages and weekly hours of work: The role of division bias. The Journal of Human Resources, 15(3), 409-423.

Bzhilyanskaya, L. Y., Cigno, M., \& Pearsall, E. S. (2015). A branching AIDS model for estimating U.S. postal price elasticities. In M. A. Crew \& T. J. Brennan (Eds.), Postal and delivery innovation in the digital economy (pp. 91-113). Cham: Springer International Publishing.

Davidson, R., \& MacKinnon, J. (2004). Econometric theory and methods. New York: Oxford University Press.

Deaton, A., \& Irish, M. (1984). Statistical models for zero expenditures in household budgets. Journal of Public Economics, 23, 59-80.

Fève, F., Magnac, T., Soteri, S., \& Veruete-McKay, L. (2018). How price sensitive is letter advertising mail in the UK. In P. L. Parcu, T. Brennan, \& V. Glass (Eds.), New business and regulatory strategies in the postal sector (pp. 207-217). Cham: Springer International Publishing.

Hin, L. Y., \& Wang, Y. G. (2009). Working-correlation structure identification in generalized estimating equations. Statistics in Medicine, 28(4), 642-658.

Liang, K. Y., \& Zeger, S. L. (1986). Longitudinal data analysis using generalized linear models. Biometrika, 73(1), 13-22.

Pan, W. (2001). Akaike's information criterion in generalized estimating equations. Biometrics, $57(1), 120-125$.

Veruete-McKay, L., Soteri, S., Nankervis, J., \& Rodriguez, F. (2011). Letter traffic demand in the UK: An analysis by product and envelope content type. Review of Network Economics, 10(3), $1-28$. 